\title{
Manual vacuum aspiration: a safe and effective surgical management of early pregnancy loss
}

\author{
Aishah Azman, Noor Asikin Mohd Sakri, Nor Adibah Mohd Kusni, \\ Nurul Hidayah Mansor, Zahar Azuar Zakaria*
}

Department of Obstetrics \& Gynaecology, Hospital Kemaman, Terengganu, Malaysia

Received: 13 April 2019

Revised: 06 May 2019

Accepted: 14 May 2019

\section{*Correspondence:}

Dr. Zahar Azuar Zakaria,

E-mail: zazuarz@yahoo.co.uk

Copyright: ( $)$ the author(s), publisher and licensee Medip Academy. This is an open-access article distributed under the terms of the Creative Commons Attribution Non-Commercial License, which permits unrestricted non-commercial use, distribution, and reproduction in any medium, provided the original work is properly cited.

\begin{abstract}
Background: Manual vacuum aspiration (MVA) is an alternative to the standard sharp uterine curettage, performed under local anaesthetic or sedation in the daycare setting. The objectives of this study were to assess the efficacy and safety of MVA, the pain perception and the factors related to it.

Methods: This was a prospective observational study of 58 consecutive patients who had undergone Manual Vacuum Aspiration (MVA) in Early Pregnancy Assessment Clinic, Hospital Kemaman between January and December 2017. Data on the patients' characteristics and the procedures were analysed.

Results: The efficacy of the procedure was $96.5 \%$ (56/58) with no major complication recorded. Majority of the patients $(91.3 \%)$ reported mild to moderate pain with $2 / 3$ of them agreed to undergo MVA in the future and would recommend it to other patients. There was no significant difference in mean pain score between different groups of women (parity, education levels, occupations, previous uterine evacuation) or procedural techniques (analgesia, sedation, cervical block, cervical dilatation, procedure duration, number of aspiration passes).

Conclusions: MVA is safe and well accepted procedure for out-patient surgical evacuation of early miscarriages.
\end{abstract}

Keywords: Early pregnancy loss, Manual vacuum aspiration, Miscarriage, Surgical evacuation

\section{INTRODUCTION}

The first report of uterine evacuation using vacuum was published in China in 1958 before the technique was later adopted, refined and popularised in the other parts of the world. ${ }^{1}$ In 1972, Harvey Karman introduced a surgical evacuation technique using syringe and vacuum known as manual vacuum aspiration (MVA) and has been used for management of miscarriages and elective termination of pregnancy since then. ${ }^{2}$ The usage was later extended to include missed miscarriage and second miscarriage/ termination with low reported complication rates.
One of the most important aspect of surgical intervention is pain control, to ensure the procedure can be completed with minimal or no distress to the patients. Analgesia that had be used in MVA include oral, rectal or parenteral analgesia, intracervical analgesia, paracervical block, Entonox, oral and parenteral opiod or combination of these techniques..$^{5-11}$ All these methods had been shown to be effective in providing pain relieve during MVA, but the factors that may contribute to the pain sensation had not been adequately addressed. Here we are discussing the pain perception of our patients during MVA and the associated factor. 


\section{METHODS}

The study was an observational study conducted in the Obstetrics \& Gynaecology Department, Hospital Kemaman, between January to December 2017. All women who had undergone MVA during the mentioned period were invited to participate.

The procedure was performed in the Early Pregnancy Assessment Clinic using a $60 \mathrm{ml}$ syringe with a selflocking mechanism (Ipas, Chapel Hill, 27514 NC) attached to a Karman curettage of an appropriate size. Where necessary, dilatation of the cervix was carried out using Denniston dilators ((Ipas, Chapel Hill, 27514 NC). According to the hospital protocol, all MVA were planned as day care procedures where patients were required to fast for at least 6 hours and were observed for at least 2 hours after the MVA before being discharged home. All patients were subjected to a transvaginal ultrasound for diagnosis of the pregnancy complication and were required to sign a written consent prior to the MVA. Products of conception were identified by visual inspection and complete uterine evacuation was confirmed by transvaginal ultrasound following the procedure in all cases, as per department's protocol.

Included in the study were women with incomplete miscarriage and anembryonic pregnancy/ missed miscarriage with the uterus size corresponding to 12 weeks gestation or less. The women were assessed to ensure that they were well motivated, can tolerate speculum examination, had no evidence of intrauterine infection and no unstable systemic disease. Exclusion criteria were cervical stenosis, presence of uterine fibroid in the uterus of more than 12 weeks gestation, uterine malformation, haemorrhagic disorder and treatment with anticoagulant, allergy or contraindication to the use of prostaglandin, analgesia or to local anaesthetic agents, uterine infection, inability to tolerate pelvic examination and retained product of conception of more than $5 \mathrm{~cm}$ (mean diameter on ultrasound).

In cases of anembryonic pregnancy or missed miscarriage, $1 \mathrm{mg}$ of gemeprost $\left(16,16\right.$-dimethyl-trans $\Delta_{2}$ PGE1 methyl ester, cervagem) was inserted intravaginal and the patient was rested for 3 hours prior to the actual MVA procedure. All patients were given oral Cefuromixe $500 \mathrm{mg}$ (or Erythromycin ethyl succinate $400 \mathrm{mg}$ ) and Metronidazole $400 \mathrm{mg}$ half an hour before the planned procedure. They were also offered oral Mefenemic acid $500 \mathrm{mg}$ or Naproxen sodium $550 \mathrm{mg}$ and/ or parenteral opiod (Pethidine $50 \mathrm{mg}$ or Nalbuphine $10 \mathrm{mg}$ ) as analgesia. Sedation (intravenous Midazolam) was also used if needed. Paracervical or cervical block using Lignocaine $2 \%$, following technique described by elsewhere, where were added if necessary, especially when cervical dilatation was needed. ${ }^{12}$

The patients' demographic data and details of the MVA procedure were recorded in a prepared format, "Manual
Vacuum Aspiration Assessment Format". The primary outcome of the analysis was to assess the efficacy of the procedure which is defined as complete uterine evacuation without the need for further intervention. Secondary outcomes include safety, the complications and the pain perception of the patient during MVA. The severity of pain was assessed using the Visual Analogue Scale (0-10), and patients were also asked about their willingness to undergo repeat procedure (in the future) and recommendation for others. Data recorded were coded and entered into SPSS version 22 (SPSS Inc, Chicago, IL, USA) software. Mean and standard deviation were calculated for the qualitative variables and comparison of pain score between two groups of variables were performed using multifactorial univariate (ANCOVA) analysis, after controlling for co-variates. $\mathrm{P}$ value of less than 0.05 was considered to indicate statistical significance.

\section{RESULTS}

In the study period of 1 year, there were a total of 147 cases of miscarriages which underwent surgical uterine evacuation. Fifty-eight cases $(39.4 \%)$ had agreed to undergo MVA while the rest underwent the procedure under anesthesia in the operation theatre. Data were available in all 58 cases of MVA (28 incomplete and 30 missed miscarriages) which were analysed in this study. Mean age of the women was 33.4 year $( \pm 6.3 \mathrm{SD})$ while the mean gravidity was $4.2( \pm 2.2 \mathrm{SD})$. Six patients $(10.3 \%)$ were in their first pregnancy while the gestational age ranged from 7 to 16 weeks with the mean of 9.3 weeks $( \pm 4.8 \mathrm{SD})$. The indication for MVA was missed miscarriage in 30 patients $(51.7 \%)$ while the rest was incomplete miscarriage. Thirteen women $(22.4 \%)$ had undergone surgical evacuation of the uterus, at least once, in the previous pregnancies.

Cervical priming with vaginal prostaglandin (gemeprost) were required in 26 (from 30) cases of missed miscarriages and six women had cervical dilatation prior to aspiration (including 5 patients who had prior cervical priming). Most of the procedures (87.9\%) were done under parenteral opiod cover while 7 patients had the procedure completed with oral nonsteroidal antiinflammatory drugs (NSAIDs) alone as analgesia. Sedation was required in about $20 \%$ of the cases including 10 patients who had received parenteral Pethidine to reduce the anxiety during the procedure (Table 1).

A total of $56 / 58(96.5 \%)$ women had successful procedures and did not require any further surgical or medical treatment. The procedure had to be abandoned in one case due to excessive bleeding, but not requiring any blood transfusion, and the evacuation was completed in the operation theatre on the same day. Another woman had incomplete evacuation and eventually managed surgically under general anaesthesia a week after MVA. There was no vasovagal reaction, cervical injury or 
uterine perforation reported. Almost half of the procedures (27/58) were completed within 15 minutes (average time was $19 \pm 6.8$ minutes) but none of the cases took more than 30 minutes. Majority of the procedures $(81 \%)$ were completed with 3 or less aspiration passes.

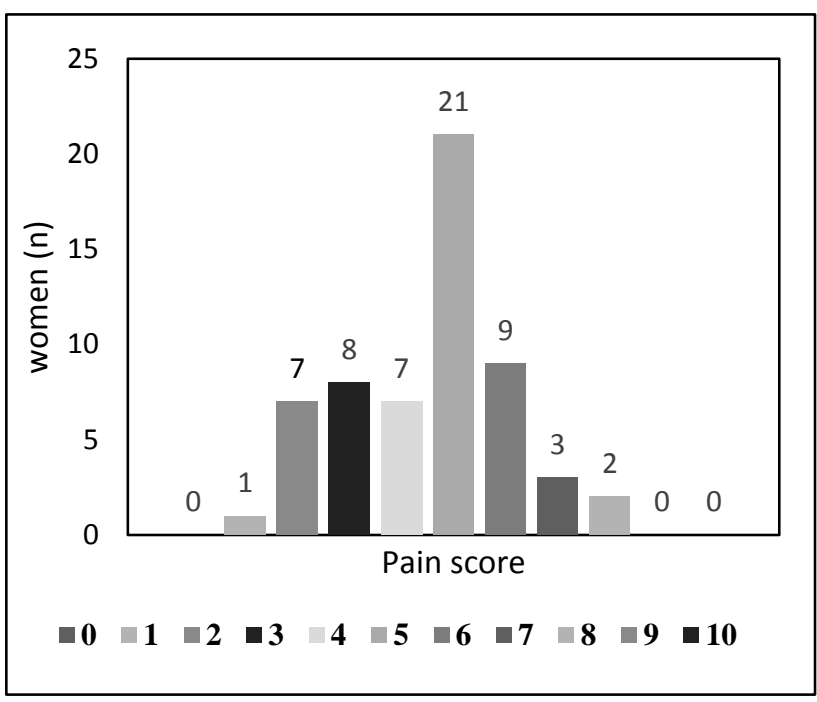

Figure 1: Pain score (n).

The pain score reported by the patients is presented in Figure 1. The mean pain score was $4.5( \pm 1.6 \mathrm{SD})$ with the lowest reported score was 1 while two respondents gave the score of 8 . More than ninety percent of the women reported the score of 6 or less which is translated into mild to moderate pain. All five women who reported severe pain (score 7 and 8/10) were multigravida and 4 of them received parenteral Pethidine as analgesia. None of them required cervical dilatation prior to MVA and all had 3 or less aspiration passes. Analysis showed that there was no significant difference in mean pain score in related to parity, occupations or education levels. Women who had previous surgical evacuation reported similar pain score compared to those who were had not. Interventions during MVA, such as the use of different analgesias (parenteral vs oral), adding sedation, the use of prostaglandin to ripen the cervix, cervical dilatation, procedure duration and number of aspirations did not give significant difference in mean pain score. The use of parenteral analgesia, adding cervical block during the procedure and cervical dilatation are associated with lower pain score although statistically insignificant (Table 1).

More than $60 \%$ of the women agreed to undergo repeat MVA in the future, including 3 who had reported severe pain earlier. Similar number (38/58) would recommend MVA to other patients who require surgical evacuation of the uterus, again including 2 women who had reported severe pain during the MVA. Majority of the women gave positive review on MVA and most quoted the short procedural duration and tolerable pain as the main reason they would agree to undergo a repeat procedure and/ or recommend it to others (Table 2).
Table 1: Relationship between patients' and procedure's characteristics with mean pain score.

\begin{tabular}{|c|c|c|c|}
\hline & $\begin{array}{l}\text { Number } \\
(\%)\end{array}$ & $\begin{array}{l}\text { Mean pain } \\
\text { score }( \pm 2 S D)\end{array}$ & $\begin{array}{l}\mathbf{P} \\
\text { value* }\end{array}$ \\
\hline \multicolumn{4}{|l|}{ Parity } \\
\hline Primigravida & $6(10.4)$ & $4.5 \pm 1.0$ & \multirow{2}{*}{0.471} \\
\hline Multipara & $52(89.6)$ & $4.5 \pm 1.6$ & \\
\hline \multicolumn{4}{|l|}{ Occupation } \\
\hline Housewives & $32(55.2)$ & $4.4 \pm 1.5$ & \multirow{2}{*}{0.671} \\
\hline Worker & $26(44.0)$ & $4.6 \pm 1.7$ & \\
\hline \multicolumn{4}{|l|}{ Education level } \\
\hline Primary education & $2(3.4)$ & $3.5 \pm 0.7$ & \multirow{3}{*}{0.110} \\
\hline $\begin{array}{l}\text { Secondary } \\
\text { education }\end{array}$ & $32(55.2)$ & $4.9 \pm 1.6$ & \\
\hline Tertiary education & $24(41.4)$ & $4.2 \pm 1.6$ & \\
\hline \multicolumn{4}{|c|}{ Past history of surgical evacuation } \\
\hline Yes & $13(22.4)$ & $4.2 \pm 2.1$ & \multirow{2}{*}{0.414} \\
\hline No & $45(77.6)$ & $4.6 \pm 1.4$ & \\
\hline \multicolumn{4}{|l|}{ Diagnosis } \\
\hline $\begin{array}{l}\text { Incomplete } \\
\text { miscarriage }\end{array}$ & $28(48.3)$ & $4.7 \pm 1.6$ & \multirow{2}{*}{ 0. 241} \\
\hline $\begin{array}{l}\text { Missed } \\
\text { miscarriage }\end{array}$ & $30(51.7)$ & $4.3 \pm 1.5$ & \\
\hline \multicolumn{4}{|c|}{ Preoperative analgesia } \\
\hline Parenteral & $51(87.9)$ & $4.4 \pm 1.6$ & \multirow{2}{*}{0.227} \\
\hline Oral & $7(12.1)$ & $5.2 \pm 1.1$ & \\
\hline \multicolumn{4}{|c|}{ Intraoperative sedation } \\
\hline Yes & $12(20.7)$ & $4.6 \pm 1.7$ & \multirow{2}{*}{0.913} \\
\hline No & $46(79.3)$ & $4.5 \pm 1.5$ & \\
\hline \multicolumn{4}{|l|}{ Cervical priming } \\
\hline Yes & $26(44.8)$ & $4.5 \pm 1.5$ & \multirow{2}{*}{0.053} \\
\hline No & $32(55.2)$ & $4.5 \pm 1.6$ & \\
\hline \multicolumn{4}{|c|}{ Intracervical analgesia } \\
\hline Yes & $4(6.9)$ & $3.8 \pm 1.5$ & \multirow{2}{*}{0.390} \\
\hline No & $54(93.1)$ & $4.6 \pm 1.6$ & \\
\hline \multicolumn{4}{|l|}{ Cervical dilatation } \\
\hline Cervical dilatation & $6(10.3)$ & $3.8 \pm 1.8$ & \multirow{2}{*}{0.547} \\
\hline No dilatation & $52(89.7)$ & $4.6 \pm 1.5$ & \\
\hline \multicolumn{4}{|c|}{ Duration of the procedure } \\
\hline 15 minutes or less & $27(46.5)$ & $4.3 \pm 1.8$ & \multirow[b]{2}{*}{0.557} \\
\hline $\begin{array}{l}\text { More than } 15 \\
\text { minutes }\end{array}$ & $31(53.5)$ & $4.6 \pm 1.4$ & \\
\hline \multicolumn{4}{|c|}{ Number of aspiration } \\
\hline Less than 3 & $12(20.7)$ & $3.9 \pm 1.2$ & \multirow{2}{*}{0.308} \\
\hline 3 or more & $46(79.3)$ & $4.7 \pm 1.6$ & \\
\hline
\end{tabular}

Table 2: Patients' satisfaction; n (\%).

\begin{tabular}{|llll|}
\hline & Yes & Unsure & No \\
\hline Agree for future & 37 & 12 & 9 \\
MVA & $(63.6)$ & $(20.7)$ & $(15.5)$ \\
\hline $\begin{array}{l}\text { Would recommend } \\
\text { to others }\end{array}$ & 38 & 19 & $1(1.7)$ \\
\hline
\end{tabular}




\section{DISCUSSION}

Although medical management of early pregnancy complication is well documented, unavailability of Misoprostol had precluded this practice in our setting. The only vaginal prostaglandin available is Gemeprost, which despite of its comparable efficacy to Misoprostol, is not cost effective due to its high cost and potential complications. $^{13,14}$ As such, sharp curretage under anaesthesia or evacuation of retained product of conception (ERPOC), has been the mainstay management of early pregnancy failure in our centre.

Our experience had shown that complete uterus emptying can be achieved in more than $96 \%$ of the case which is similar to other studies reporting the success rate of more than $95 \% .^{7,15-18}$ The procedure itself is not complicated, with minimal intervention and low incidence of complications. Major complications of MVA such as excessive bleeding requiring blood transfusion, uterine perforation and hospitalization were reported to be less than $1 \%$ and none recorded in our study. ${ }^{18,19}$

In our study, Visual Analogue Scale was chosen due to its ease of use, and widely used in other studies. ${ }^{12,20}$ Using opiods as the analgesia, most of our patients (90\%) reported mild to moderate pain (score of 7 or less) during the procedure with the mean score of 4.5 , comparable to a study using Meperidine (mean score 5.7; 59\% reported mild to moderate pain). ${ }^{8}$ Parenteral opiods especially intramuscular Pethidine was the preferred choice among our doctors due to extensive experience of its used in our centre for women in labour and for manual removal of placenta.

Data also shows that the intraoperative pain is tolerable with none of the procedures were terminated due to pain or vasovagal reaction, and none of the cases required additional pain relief. The use of additional cervical block and sedation was not due to intolerable pain but depends on the doctor's assessment of the individual patient before the actual procedure and adding these did not significantly change the patients' perception of pain, as stated above.

More than half of the study subjects would consider MVA should they have another complicated miscarriage, including 10 who had undergone sharp curettage under anaesthesia in previous pregnancies. This is slightly lower than other studies which reported the figure of about $75-80 \% .^{7,17}$ In another aspect, the same studies reported $83-86 \%$ of the women who underwent MVA would they would recommend the procedure, higher than our findings at $66 \%$, probably due to different study populations.

\section{CONCLUSION}

Manual vacuum aspiration had been shown in numerous studies including our recent experience, to be a safe and well tolerated alternative to the traditional surgical evacuation of retained product of conception. Additional procedures during the MVA, do not significantly alter the pain experienced by the patients.

\section{Funding: No funding sources}

Conflict of interest: None declared

Ethical approval: The study was approved by National Medical Research Registry (Malaysia)

\section{REFERENCES}

1. $\mathrm{Wu} \mathrm{Y,} \mathrm{Wu} \mathrm{X.} \mathrm{A} \mathrm{report} \mathrm{of} 300$ cases using vacuum aspiration for the termination of pregnancy. Chinese J Obstet Gynecol. 1958;447-9.

2. Karman H, Malcom P. Very early abortion using syringe as vacuum source. The Lancet. 1972;299(7759):1051-2.

3. Todd CS, Soler ME, Castleman L, Rogers MK, Blumenthal PD. Manual vacuum aspiration for second-trimester pregnancy termination. Int $\mathbf{J}$ Gynaecol Obstet. 2003;83(1):5-9.

4. Milingos DS, Mathur M, Smith NC, Ashok PW. Manual vacuum aspiration: a safe alternative for the surgical management of early pregnancy loss. BJOG. 2009;116(9):1268-71.

5. Edelman A, Nichols MD, Jensen J. Comparison of pain and time of procedures with two first-trimester abortion techniques performed by residents and faculty. Am J Obstet Gynecol. 2001;184(7):1564-7.

6. Gómez PI, Gaitán H, Nova C, Paradas A. Paracervical block in incomplete abortion using manual vacuum aspiration: randomized clinical trial. Obstet Gynecol. 2004;103(5 Pt 1):943-51.

7. Hamoda H, Flett GM, Ashok PW, Templeton A. Surgical abortion using manual vacuum aspiration under local anaesthesia: a pilot study of feasibility and women's acceptability. J Fam Plann Reprod Health Care. 2005;31(3):185-8.

8. López JC1, Vigil-De Gracia P, Vega-Malek JC, Ruiz E, Vergara V. A randomized comparison of different methods of analgesia in abortion using manual vacuum aspiration. Int $\mathrm{J}$ Gynaecol Obstet. 2007;99(2):91-4.

9. Iftikhar G, Abbad Gilani ST. Comparison of manual vacuum aspiration and sharp curettage in the treatment of first trimester abortions. Pak Armed Forces Med J. 2014;64(4):541-5.

10. Pillai M, Welsh V, Sedgeman K, Gazet AC, Staddon J, Carter H. Introduction of a manual vacuum aspiration service: a model of service within a NHS Sexual Health Service. J Fam Plann Reprod Health Care. 2015;41(1):27-32.

11. Ansari A, Abbas S. Manual Vacuum Aspiration (MVA) - A safe option for evacuation of first trimester miscarriage in cardiac patients. J Pak Med Assoc. 2017;67(6):948-50.

12. Mankowski JL1, Kingston J, Moran T, Nager CW, Lukacz ES. Paracervical compared with intracervical lidocaine for suction curettage: a 
randomized controlled trial. Obstet Gynecol. 2009;113(5):1052-7.

13. Celentano C, Prefumo F, Di Andrea O, Presti F, Di Nisio Q, Rotmensch S. Oral misoprostol vs. vaginal gemeprost prior to surgical termination of pregnancy in nulliparae. Acta Obstet Gynecol Scand. 2004;83(8):764-8.

14. Svendsen PF, Rørbye C, Vejborg T, Nilas L. Comparison of gemeprost and vaginal misoprostol in first trimester mifepristone-induced abortion. Contraception. 2005;72(1):28-32.

15. Edward J, Creinin MD. Early abortion: surgical and medical options. Curr Prob Obstet Gynecol Fertil. 1997;20(1):6-32.

16. Westfall JM, Sophocles A, Burggraf H, Ellis S. Manual vacuum aspiration for first-trimester abortion. Arch Fam Med. 1998;7(6):559-62.

17. Zhang J, Gilles JM, Barnhart K, Creinin MD, Westhoff C, Frederick MM, et al. A comparison of medical management with misoprostol and surgical management for early pregnancy failure. $\mathrm{N}$ Engl $\mathbf{J}$ Med. 2005;353(8):761-9.

18. Wen J, Cai Q, Deng F, Li Y. Manual versus electric vacuum aspiration for first-trimester abortion: a systematic review. BJOG. 2008;115(1):5-13.

19. White K, Carroll E, Grossman D. Complications from first-trimester aspiration abortion: a systematic review of the literature. Contraception. 2015;92(5):422-38.

20. Miller L, Jensen MP, Stenchever MA. A doubleblind randomized comparison of lidocaine and saline for cervical anesthesia. Obstet Gynecol. 1996;87(4):600-4.

Cite this article as: Azman A, Sakri NAM, Kusni NAM, Mansor NH, Zakaria ZA. Manual vacuum aspiration: a safe and effective surgical management of early pregnancy loss. Int J Reprod Contracept Obstet Gynecol 2019;8:2256-60. 